Cole, E. , Erdman, E \& Rothblum, E. (Eds) (1994) Wilderness. Therapy for Women: The power of adventure

Harrington Park Press. ISBN 1560230584

To purchase in Australia contact Johima Pty Ltd (02) 96871922.

Twenty-six authors contribute to this anthology of different female perspectives on wilderness and adventure experiences for women. The book comprises of four sections: theoretical perspectives, wilderness therapy in action, special populations and a section on personal rarratives. Topics include: body image, ethical considerations, use of ropes courses, wilderness therapy with survivors of sexual assault, solo experiences and equine therapy. The diversity of authors and respective approaches and perspectives bring a refreshing range of new dimensions seldom written about by the male dominated literature. However, this variation presents the reader with an often disjointed and subjective journey over many topic areas. In many ways, the book's strengths are also its weaknesses. Theoretical positions are seldom articulated and are at times in apparent tension with one another. For example, different variations on the application of feminist perspectives to the subject matter.

These overall shortfalls, and some less-thanscholarly chapters shouldn't overshadow some very important essays. While chapters such as those by Powch on wilderness therapy theory and Levine on sexual assault survivors are disappointingly written and make unstated assumptions about women's issues, clear and succinct analyses by Australian Jackie Kiewa touch on important issues around self-control and self-mastery versus mastery and control of the environment. In a well researched and cited paper, Arnold discusses important issues around body image and notions of aesthetic versus functional values which relates well to clinical issues and presentations.

It is pleasing to see Mitten's discussion on ethical issues relevant to women which provides a thought provoking challenge to many assumptions about the therapeutic value of stress. Similarly, Asher, Huffaker \& Nally's account of work with rape and incest survivors is strong and forthright in their criticism of traditional wilderness programs, raising a number of relevant ethical issues particularly around the dangers of taking a universal group versus an individualised approach. However, some conclusions such as the chapter by Aubrey \& MacLeod on career planning seem a little too far from the periphery of therapy.

Major criticisms are that there seems no central tenants of theses put forward but rather the beginning of ideas which could be explored more. Much reference is made to 'feminist theory' without this ever being discussed or delineated. It is very laden with North American cultural values and assumptions, for example when the authors comment on ethnic and cultural issues. Generally, tighter editing is required as the book lacks structure and coherence. Better citation and more detailed and critical analysis of the literature would enhance its appeal to a more academic readership. The choice of topics sound promising but are brief and unconvincing and tend to rely on an overuse of testimony in an attempt to convince the reader.

In conclusion, this book is confused as to whether it is an academic text, feminist critique, therapists' handbook or testimonial. While it fails to be any of these successfully, it is still a most valuable resource. As a text in itself it should be supplemented by more generalist texts on wilderness and adventure therapy.

However, this book will be of value and interest to the practitioner and researcher because of the fertility of ideas and novel perspectives which are lacking in many current texts. It should be mandatory reading for therapists or professionals involved in conduction outdoor wilderness and adventure activities because of the uniquely female perspective it brings.

\section{Simon Crisp}

* This review was previously published in the Australian Psychologist, 32 , 3,216-217.

*PLEASE NOTE*

If you would like to review a book for future editions of the AJOE - please contact Tonia Gray 